\title{
Situación de la la Porcinocultura en el Ecuador
}

\section{Dr. Vet. Rafael Ochoa Méndez}

a porcinocultura ecuatoriana enfrenta retos cada vez más difíciles de vencer, los mismos que nos obligan a buscar tecnologías que ayuden a alcanzar mayores niveles de producción y a su vez le permitan ser más competitivas.

Por esta razón podemos ver como son aplicados conceptos nuevos en manejo, nutrición, administración, salud animal, reproducción, entre otros. En esta última área es donde la inseminación porcina ha venido difundiéndose de manera muy rápida. En América la porcinocultura canadiense es la que esta liderando en la aplicación de la inseminación artificial porcina.

En el país se esta utilizando esta técnica de la mejor manera, con la finalidad de obtener resultados que nos ayuden a mejorar, nuestra genética y al mismo tiempo incrementar la producción del área porcina.

En el Austro Ecuatoriano la inseminación artificial porcina no se encuentra difundida, por la falta de personal o técnicos que pongan al servicio del porcinocultor especialmente de las provincias del Azuay y Cañar. Siendo otra causa el desconocimiento de la técnica de inseminación o la falta de difusión por parte de entidades estatales y privadas por lo que también se recomienda que los centros de formación, como Universidades o Escuelas Politécnicas capaciten personal y pongan sus servicios a la disponibilidad de los porcicultores de la Región.

\section{Desarrollo de la inseminación artificial porcina en el Ecuador}

En el Ecuador más del $80 \%$ de la producción nacional de cerdas se encuentran el estrato de explotaciones que poseen de 1 a 4 cerdas de cría. Aproximadamente el $50 \%$ de estas unidades no disponen de reproductor; a menudo el verraco de una finca, generalmente criollo, es alquilado o el productor en- trega de 1 a 2 crías por la monta. (CIAT 1998).

Con este antecedente, la adaptación de la tecnología de inseminación artificial es una opción válida para mejorar la producción de las cerdas y productividad de las crías, especialmente del Cantón Paute y Gualaceo; regiones donde el consumo de carne de cerdo cada vez va alcanzando porcentajes superiores.

Por lo que resulta urgente difundir o implantar la inseminación artificial porcina, utilizando nuevas razas con mayores aptitudes para afrontar mejor la producción de carne al desposte y con mejor densidad de grasa.

\section{Concepto de inseminación}

La inseminación artificial, puede definirse como el método reproductivo por el cual se sustituye el apareamiento entre el macho y la hembra por un sistema en donde el material espermático es depositado a través de instrumentales en las vías genitales femeninos, en donde interviene el hombre.

La inseminación artificial es la técnica individual más importante creada para el mejoramiento genético de animales.

\section{Ventajas:}

- Disminuye el número de varracos con ahorro de espacio y de costos de mantenimiento.

- Difusión rápida del progreso genético, mejorando los rendimientos al utilizar sementales de mayor valor genético, obteniendo una mejora más rápida en las explotaciones porcinas.

- Se puede realizar un buen programan de cruzamientos ya que podemos utilizar solo verracos de reconocido mérito zootécnico.

- Producción de lotes más homogéneos con destino al matadero.

- Se reduce la entrada de animales portadores de enfermedades infecto-contagiosas por vía sexual

- Ahorro de tiempo y esfuerzo evitando la monta natural y el desplazamiento de los reproductores

- Uso de animales de distinto peso.

\section{Momenoto optimo para la inseminación artif icial}

\section{Deteccion del celo}

La importancia de la detección del celo en el sistema e inseminación artificial no debe ser sobreestimada. Es absolutamente vital para el éxito de cada inseminación que el productor sea exacto en al estimación del inicio del estro. Es más afectivo detectar el estro dos veces al día, 7 am y 5 pm. 
Las cerdas adultas se inseminan 24 horas después de presentar quietud de monta, mientras que las primíparas deben inseminarse 12 horas, dado a que el celo es de menor duración.

\section{Demasiado pronto}

- Vulva muy enrojecida o hinchada

- Sin moco en la mucosa vaginal

- Prueba de presión dorsal negativa.

\section{A tiempo}

- Vulva medianamente enrojecida e hinchada.

- Mucosa vaginal con moco

- Prueba de presión dorsal positiva.

\section{Demasiado tarde}

- Sin enrojecimiento e hinchazón vulvar.

- Mucosa vaginal pegajosa.

- Prueba de presión dorsal negativa, solo presenta reflejo de inmovilidad al verraco.

El celo de la cerda de 2 - 3 horas en cerdas primíparas dura 48 horas y en cerdas multíparas 72 horas.

\section{Tecnicas de inseminación}

Es buena idea evaluar la calidad del semen con un microscopio, antes de usarlo, ya que el transporte, dilución, temperatura de almacenamiento, a fluctuaciones de temperatura y el tiempo transcurrido desde la colección, puede afectar su vida útil, motilidad y vialidad.

- Use una toalla de papel para limpiar la vulva antes de proceder a la inseminación.

- Lubrique el extremo de la pipeta o catéter con lubricante que no sea espermicida.

- Introduzca cuidadosamente el instrumento, con la punta hacia arriba pro la vagina hasta el vervix, la botella con el semen diluido no se conecta todavía con el catéter; una razón de esta es no exponer la botella innecesariamente a excesos de luz o temperatura.

- Cuando se usa catéter, realizar una rotación en sentido contrario a las agujas del reloj lo hará penetrar en la cerviz. En este momento se puede sentir cierta resistencia al halar de la pipeta hacia atrás.

- Invierta cuidadosamente dos a tres veces la botella que contiene el semen diluido para mezclarlo. Sujete la botella en el extremo del catéter y descargue lentamente el semen, este proceso dura por lo menos 3 minutos. Si se deposita muy rápido causa reflujo por la vulva y existe desperdicio. Recuerde que usted esta tratando de reemplazar al verraco, que necesita de 10 a 20 minutos en cada monta.

- Cuando se ha depositado dentro de la hembra todo el semen extraiga la pipeta haciéndola girar en el sentido de las agujas de reloj, hay quienes recomiendan dejar el catéter en posición varios minutos para prolongar la estimulación cervical.

- Mantenga a la hembra en un sitio tranquilo por 20 a 30 minutos, cualquier inquietud en estos momentos puede interrumpir el transporte el semen y la fertilización.
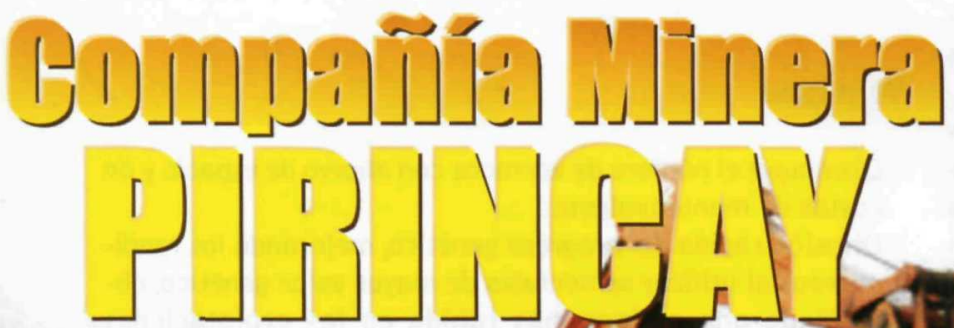

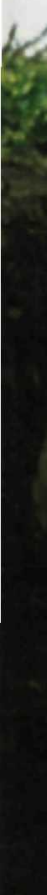

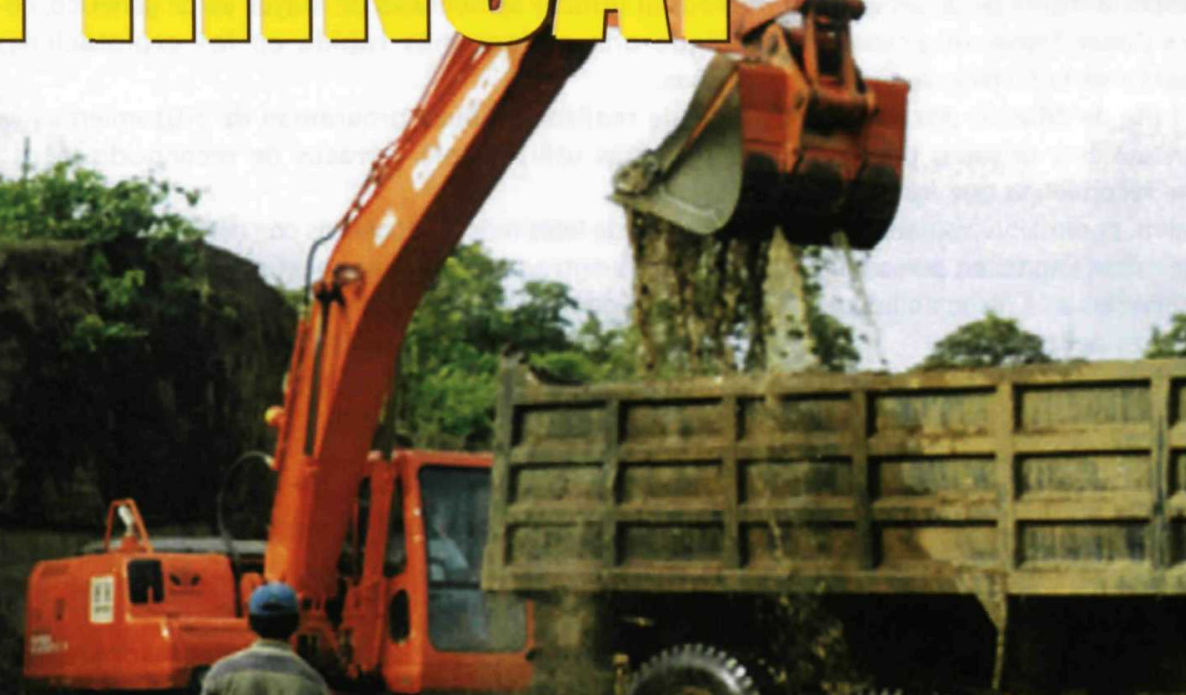

- Saluda la creación de la Escuela de Ingeniería Ambiental, de la Facultad de Ciencias Pecuarias y Agroindustriales y se compromete a trabajar juntos pro la preservación del Medio Ambiente. 